\title{
STUDY OF THEORY, METHOD, APPLICATION OF GOTHIC CHURCH ARCHITECTURE
}

\author{
KaJian TeOri, Metode, APlikasi \\ ARSITEKTUR GereJa GothIC
}

\author{
Adimas Kristiadi \\ Program Studi Arsitektur, Fakultas Arsitektur dan Desain, UKDW \\ adimas.kristiadi@staff.ukdw.ac.id
}

\begin{abstract}
The architecture of Gothic church is the outcome from creation process of knowledge by human in $12^{\text {th }}-15^{\text {th }}$ Century which originating from France, which one the evolution from Romanesque church architecture $\left(10^{\text {th }}-13^{\text {th }}\right.$ Century). The word of "evolution" is being a keyword and be a reason of Gothic church, to change characters from Romanesque church architecture are monastic buildings (not large), heavy in appearance, simple in construction to be a larger and finer, much details and symbols, construction and ornament is advancing and improving, there is an effort to enter natural lighting. There is competition in $12^{\text {th }}-15^{\text {th }}$ Century about bigger and magnificent building of church in Europe. The method is literature studies with analytical descriptions. The results are: The basic theory of evolution is dignity, Gothic church architecture is built with the intention of giving honor of the highest to God. The concepts are verticalism, transparent, religious symbolism. The methods is following the concepts that are heighten (heightening structure), mitigate (lightening structure), brighten (natural lighting), symbolize (enrich symbols). The application is realized with: floor plan as cross, pointed arch, ribbed vault, flying buttress, pinnacles, flamboyant decoration, large windows filled with rich stained glass.
\end{abstract}

Keywords: Gothic Architecture, Romanesque Architecture, Church, Theory, Concept, Method, Application

\section{LATAR BELAKANG}

Gaya arsitektur Gothic berkembang dari Perancis (French style) pada periode pertengahan yaitu sekitar abad $12-15$. Sebenarnya nama 'Gothic' merupakan ejekan yang dihubungkan dengan orang-orang Goth yaitu bangsa Jerman yang pada era itu merupakan bangsa yang barbar. Disebutkan Poynter (2010) dalam buku elektronik Architecture Gothic and Renaissance,"The word Gothic, which was in use in the eighteenth century, and probably earlier, was invented at a time when a Goth was synonymous with everything that was barbarous; and its use then implied a reproach. Nama ejekan 'Goth' yang berubah menjadi 'Gothic' muncul seiring masa berakhirnya era arsitektur Gothic. Kata tersebut diciptakan orang-orang pada era Renaissance yang muncul pada abad ke 16 - 18 untuk meremehkan kegagalan ahli bangunan arsitektur Gothic dalam mengikuti mutu klasik zaman Yunani dan Romawi. Orang-orang Renaissance menganggap bahwa seluruh perkembangan kebudayaan adalah berasal dari Italia, sedangkan budaya diluar Italia begitu diremehkan dan dianggap tidak sebaik kebudayaan yang berasal dari Italia.

Gaya arsitektur Gothic merupakan adaptasi dari arsitektur Romawi, termasuk juga arsitektur gerejanya. Maksudnya adalah beberapa elemen dalam gaya arsitektur gereja Gothic merupakan 
evolusi dari elemen arsitektur gereja Romawi. Bentuk evolusi dari gaya arsitektur Romawi yang terdapat pada gaya arsitektur Gothic adalah suatu ide yang menekankan bahwa gaya arsitektur Gothic berusaha menghilangkan kesan gemuk, tebal, berat, tertutup, dan suram menjadi lebih ringan, ramping, terang namun secara menyeluruh keseimbangannya tetap dipertahankan, Poynter (2010), "Down to the eleventh century the buildings erected (almost exclusively churches and monastic buildings) were not large or rich, and were heavy in appearance and simple in construction. Their arches were all semicircular". Bentuk adaptasi gaya arsitektur gereja Gothic dari gaya arsitektur Romawi yang lain adalah, adanya kesamaan penggunaan material bangunan, penggunaan struktur atap lengkung (vault), penggunaan bentuk denah salib yang mengikuti aturan denah gereja gaya arsitektur Romawi, dan pemakaian hiasan puncak menara pada bangunan gereja pada gaya arsitektur Romawi (Cole, 2002).

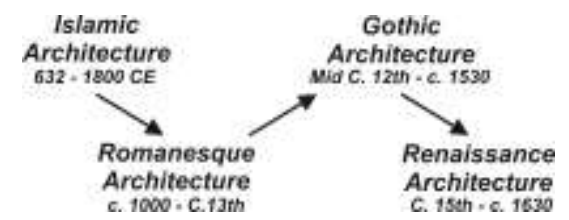

Gambar 1. Bagan alur perkembangan Arsitektur Islam hingga Arsitektur Renaissance

Sumber: Pengembangan dari buku Emily Cole

(2002) The Grammar of Architecture, 2014

Terdapat 2 (dua) filosofi gereja Gothic (Poynter, 2010), yang pertama adalah adanya garis vertikal yang merupakan garis maya dari bawah ke atas yang merupakan perlambang dari ciri zaman atau era yang mengarah total pada Yang Maha Tinggi. Garis vertikal merupakan penghubung antara manusia yang ada di bawah dengan Tuhan yang berada di atas. Filosofi yang kedua adalah diafan, yang berarti cahaya yang menembus jernih, terang, dan bening, memberikan keleluasaan cahaya dalam bangunan. Diafan ini melambangkan rahmat Tuhan yang menembus kefanaan hidup manusia untuk meneranginya dengan NurIllahi. Ciri-ciri gereja dengan gaya arsitektur Gothic adalah (Cole, 2002):
1) Denah bangunan yang berbentuk salib seperti era gaya sebelumnya yaitu gaya arsitektur Romawi

2) Pointed arch (pelengkung sudut) adaptasi dari gaya arsitektur Romawi dan era sebelumnya

3) Ribbed vault (kubah berusuk) adaptasi dari gaya arsitektur Romawi dan era sebelumnya

4) Flying buttres (penpoang layang)

5) Pinnacles (hiasan puncak menara) adaptasi dari gaya arsitektur Romawi

6) Flamboyant decoration (dekorasi yang semarak)

7) Large windows filled (jendela yang besar),

8) With rich stained glass (dengan kaca patri) Peneliti mencoba untuk mengkaji (mempelajari dan menyelidiki) bagaimana proses penciptaan pengetahuan oleh manusia mengenai arsitektur gereja Gothic. Adapun proses penciptaan pengetahuan secara akademik diakhiri oleh munculnya suatu teori (seperangkat proposisi atau sistem tentang gagasan dan pernyataan yang diyakini dapat menjelaskan suatu fenomena secara ilmiah) (Wahid, J \& Alamsyah, B, 2013). Teori dalam ranah arsitektur merupakan dasar penjelasan yang membantu dalam proses pelaksanaan perancangan. Sedangkan konsep adalah penjabaran yang lebih umum mengenai teori yang ada. Cara atau langkah untuk membuktikan suatu teori dapat disebut dengan metode. Aplikasi sendiri adalah hasil dari teori yang sudah dijabarkan konsepnya dan dibuktikan melalui metode yang sudah dilakukan. Penulis mempelajari apa yang menjadi teori dari arsitektur gereja Gothic, bagaimana pembuktian teori tersebut melalui suatu metode yang sudah dilakukan, dan apa hasil teori yang sudah dibuktikan melalui aplikasi yang tercipta pada elemen-elemen arsitektur gereja Gothic.

\section{METODE}

Penelitian ini menerapkan studi terhadap dokumen-dokumen yang mendukung (studi literatur), mencari referensi yang relevan dengan topik yang dibahas. Data primer diperoleh secara langsung melalui buku, jurnal, serta melalui media internet yang dapat 
dipertanggungjawabkan. Data tekstual yang diperoleh dianalisis dengan metode deskriptif (Kutha, 2010), mendeskripsikan fakta-fakta yang ditemukan kemudian disusul dengan analisis yang semata-mata tidak hanya menguraikan melainkan juga memberi pemahaman dan penjelasan secukupnya hingga memperoleh kesimpulan. Melihat dari metode penelitian (studi literatur) yang dipilih, proses dan hasil dari pembahasan merupakan secuil hipotesis dari suatu kesimpulan yang bersifat holistik namun sampai saat ini belum terkristalkan. Diharapkan secuil hipotesis dari peneliti ini dapat melengkapi kesimpulan tentang arsitektur gereja Gothic yang sedang atau sudah disusun oleh peneliti lainnya.

\section{HASIL DAN PEMBAHASAN}

Analisis mengenai kajian teori dapat dilakukan dengan cara menganalisis kutipan-kutipan yang mempunyai hubungan secara konstan dari literatur mengenai arsitektur gereja Gothic. Kemudian analisis juga dilakukan secara formal (berdasarkan bentuk fisik dan simbol) dengan melihat ciri-ciri yang melekat pada bangunan arsitektur gereja Gothic.

\subsection{Analisis Tekstual Arsitektur Gaya Gothic}

Poynter (2010), “The Roman empire had introduced into Europe something like a universal architecture. Down to the eleventh century the buildings erected (almost exclusively churches and monastic buildings) were not large or rich, and were heavy in appearance and simple in construction. Their arches were all semicircular...The eleventh century thus became a time of great religious activity; and if the First Crusade, which took place 1095, may be taken as one outcome of that pious zeal. Keen rivalry raged among the builders of these churches; each one was built larger and finer than the previous examples, and the details began to grow elaborate. Construction and ornament were in fact advancing and improving".

Cole (2002), "Sculptural decoration initially followed late-Romanesque forms, but soon found its own momentum and by the $13^{\text {th }}$ century the gothic style had truly broken free, in form and decoration".
Dari kutipan di atas, ditemukan kesamaan arti yang mempunyai hubungan bahwa arsitektur gereja Gothic merupakan evolusi dari arsitektur gereja Romawi. Pada era kekaisaran Romawi sekitar abad 11, gaya arsitekturnya sangatlah universal dan merajai Eropa sehingga bangunan di setiap koloni Romawi termasuk bangunan gerejanya memiliki kemiripan yang kuat. Gereja memiliki karakter bangunan yang monastic (kesan gemuk, berat dan suram dalam penampilan), strukturnya hanya memiliki lengkungan setengah lingkaran. Munculnya Perang Salib tahun 1095 menciptakan adanya semangat kesalehan terhadap agama (khususnya Kristiani). Persaingan tajam berkecamuk untuk pembangunan gereja-gereja yang lebih besar di Eropa. Gereja-gereja tersebut dibangun lebih besar dan lebih halus dengan dekorasi ornamen yang rumit dan semakin maju. Pada abad 12 saat dimulainya era Gothic terjadi perkembangan yang luar biasa. Gaya arsitektur Gothic memiliki penyelesaian dekorasi bangunan yang semakin detail dengan ornamen yang semakin hidup/natural dibandingkan dengan gaya arsitektur Romawi (disinilah era munculnya kaca patri). Namun dengan perkembangan seni yang pesat tersebut ternyata hal itu sulit diterima, dan hal tersebut dianggap suatu "seni yang menyimpang" dari kaidah seni yang ada di era tersebut. Pada era tersebut (abad 12) ada anggapan bahwa seni dari Romawi adalah yang terbaik. Pada abad 13 arsitektur Gothic menemukan momentum sendiri dan arsitektur Gothic merupakan gaya arsitektur yang bebas dalam bentuk dan dekorasi (tidak terikat oleh gaya Romawi lagi).

Poynter (2010), "All the germs of Gothic architecture exist in the Romanesque of the eleventh and twelfth centuries, and became developed as the passion for more slender proportions, greater lightness, and loftiness of effect, and more delicate enrichment became marked...The proportions of Gothic buildings were well studied, their forms were always lofty, their gables sharp, and their general composition more or less pyramidal".

Cole (2002), "Increased verticality, a reduction in wall mass and the admittance of light through large windows filled with rich stained glass were the results; they were to be taken to further and further extremes as gothic developed". 
Dari kutipan di atas, ditemukan kesamaan arti bahwa ada usaha peningkatan vertikalitas dan pemasukan cahaya serta penyimbolan pada bangunan arsitektur gereja Gothic. Arsitektur gereja Gothic pada abad 11-12 khususnya untuk karakter bentuk, dikembangkan untuk proporsi yang lebih ramping, besar namun ringan, ada efek keagungan yang terlihat, dan ada peng-kayaan simbolisme bangunan. Pointed arch secara universal diakui sebagai lencana arstitekur gereja Gothic. Bentuk dari atapnya selalu tinggi dan tajam berkomposisi seperti pyramidal. Ada penurunan massa pada dinding dan ada usaha peningkatan masuknya cahaya melalui jendela besar dengan kreasi kaca patri. Dengan dasar kutipan bahwa arsitektur gereja Gothic merupakan evolusi dari arsitektur gereja Romawi dan ada usaha peningkatan vertikalitas dan pemasukan cahaya serta penyimbolan pada bangunan gereja arsitektur Gothic dari karakteristik arsitektur gereja Romawi yang monastic (tidak besar, tidak kaya, berat dan suram dalam penampilan), maka untuk analisis berikutnya penulis akan melihat ciri-ciri dari gereja arsitektur Gothic, mengkomparasikan dengan bangunan gereja Romawi.

\subsection{Analisis Tekstual Ciri-Ciri Arsitektur Gereja Gaya Gothic}

\section{Ribbed vault}

Poynter (2010), "With the Gothic period the use of intersecting, and as a result of pointed arches, was introduced into vaulting...Vaults are met with in Renaissance buildings, but they are a less distinctive feature of such buildings than they were in the Gothic period".

Ribbed vault struktur rusuknya saling berpotongan berbentuk lengkungan bersudut atau pointed arch, dan ini merupakan struktur khas Gothic. Ribbed vault dapat dijumpai juga pada arsitektur Renaissance namun hal itu merupakan fitur yang tidak khas bagi arsitektur Renaissance.

\section{Pointed arch}

Poynter (2010), "The Semicircular and the Stilted Semicircular Arch were the only arches in use till the introduction of the Pointed Arch".
Cole (2002), "Pointed arch allowed a greater height to be achieved than did a semicircular arch".

Pointed arch atau pelengkung sudut adalah evolusi dari pelengkung setengah lingkaran. Memiliki ketinggian yang lebih besar untuk dicapai daripada pelengkung setengah lingkaran. Dimana pelengkung sudut memiliki perbandingan $\geq 1: 2$ dan pelengkung setengah lingkaran memiliki perbandingan 1:2 (1 untuk tinggi dan 2 untuk lebar).

\section{Flying buttress}

Poynter (2010), "A distinguishing feature of Gothic walls is the buttress.. A buttress used to steady the upper and inner walls of a vaulted building".

Cole (2002), "The flying buttress transmits the thrust of the vault to the ground, thereby relieving the wall. As a result, this can be lighter in construction, with a greater proportion of windows".

Flying buttress adalah struktur penopang untuk menstabilkan bagian atas bangunan berkubah pada gereja Gothic. Struktur tersebut mentransmisikan tekanan dari rib vault ke tanah, tanpa melalui dinding.

\section{Pinnacles}

Poynter (2010), "Pinnacles were frequently added at the corners of the tower, and an arch, like that of a flying buttress, was sometimes thrown across from the pinnacle to the spire. The general proportions of the spire were more slender than before".

Pinnacles (hiasan puncak menara) ditambahkan di sudut atas bangunan (pointed arch, flying buttress). Proporsi umum hiasan puncak menara ini lebih ramping dan lebih tinggi serta lebih detail dari gaya arsitektur Romawi.

\section{Large windows and stained glass}

Cole (2002), "Increased the admittance of light through large windows filled with rich stained glass were the results".

Poynter (2010), “..but there was one ornament, the crowning invention of the Gothic artists, which largely influenced the design of the finest buildings, and which reflected a glory on them such as nothing else can approach: this was 
stained glass...stained-glass windows must be something quite different from transparent pictures, and the scenes they represent must not detach themselves too violently from the general ground".

Jendela besar dengan kaca patri merupakan hasil usaha seniman pada era abad 12 untuk meningkatkan penerimaan cahaya di dalam bangunan Gothic. Kaca patri merupakan persembahan karya yang dianggap terbaik dari seniman yang mencerminkan kemuliaan. Kaca patri digunakan sebagai dekorasi cahaya dengan gambar transparan, biasanya menampilkan adegan tentang kebaikan yang melepaskan kejahatan dari dunia fana.

\section{Floor plan}

Poynter (2010), "The main axis of the building was always east and west. The plan (or main floor) of the building almost always displays the form of a cross".

Dari kutipan di atas dapat dijelaskan bahwa sumbu utama bangunan Gothic selalu Timur dan Barat, dengan pintu masuk yang berada di ujung Barat dan altar di ujung Timur. Denah lantai utama selalu menampilkan bentuk salib. Batang salib bagian barat disebut nave (tempat duduk jemaat) dan batang bagian timur disebut choir (tempat paduan suara) dan ditengah batang salib itu adalah cross.

\section{Flamboyant decoration}

Poynter (2010), "This passion for elaborate mouldings, often extraordinarily undercut, reached its climax in the thirteenth century... Ornaments abounded, and included not only enrichments in the shape of carved foliage and figures, statuary, mosaics, and so forth".

Poynter (2010), "In each period these are distinct in design, and thus to catch the spirit of any one Gothic period aright".

Gairah mengenai seni tentang "kerumitan" mencapai puncaknya pada abad 13 . Hal tersebut dibuktikan dengan adanya ornamen yang berlimpah, pengayaan dalam bentuk ukiran dan motif, patung, mosaic pada bangunan. Pada periode Gothic muncul semangat perubahan dimana setiap hiasan dekorasi harus ditempa dengan curahan semangat yang sejati oleh para seniman.

\subsection{Analisis Formal Ciri-Ciri Arsitektur Gereja Gaya Gothic}

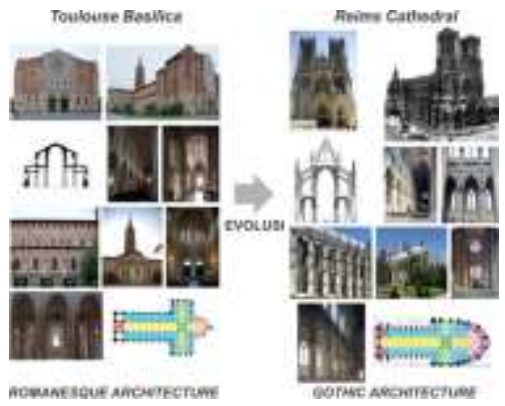

Gambar 2. Gaya arsitektur gereja Gothic merupakan evolusi dari gaya arsitektur gereja Romawi

Sumber: Pengembangan dari http://mappinggothic.org/building/1044, diakses 3 Mei 2014

Arsitektur gereja Gothic merupakan evolusi dari arsitektur gereja Romawi. Gereja Gothic berusaha untuk menghilangkan karakteristik gereja Romawi yang monastic. Penulis mengambil sampel literatur dari arsitektur gereja Romawi (Toulouse Basilica) dengan arsitektur gereja Gothic (Reims Cathedral) untuk membantu melihat secara bentuk (formal) agar memudahkan dalam penyajian analisis faktual.

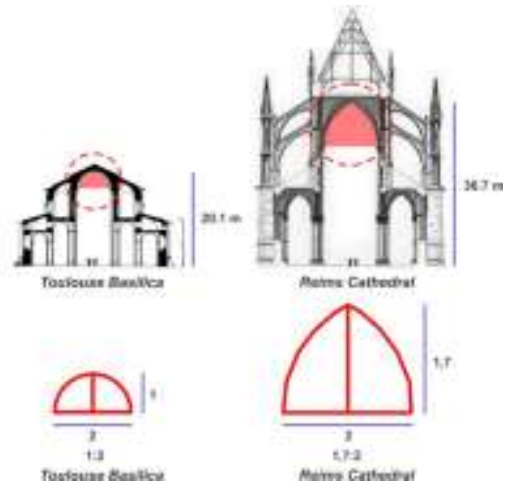

Gambar 3. Proporsi tinggi Toulouse Basilica dan Reims Cathedral

Sumber: Pengembangan dari

http://mappinggothic.org/building/1044, diakses 3

\section{Mei 2014}

Terlihat pada perbandingan gambar potongan antara Toulouse Basilica dengan Reims Cathedral, proporsi lebih tinggi dan lebih besar ada pada gereja Gothic dengan tinggi langitlangit kubah $\pm 36,7 \mathrm{~m}$ berbanding $\pm 20,1 \mathrm{~m}$ (didapatkan dari gambar skala manusia). 
Pemakaian pelengkung setengah lingkaran untuk vault yang ada pada Toulouse Basilica telah berubah menjadi pelengkung sudut (pointed arch) pada Reims Cathedral. Pelengkung sudut pada arsitektur gereja Gothic membuat struktur vault menjadi lebih tinggi.

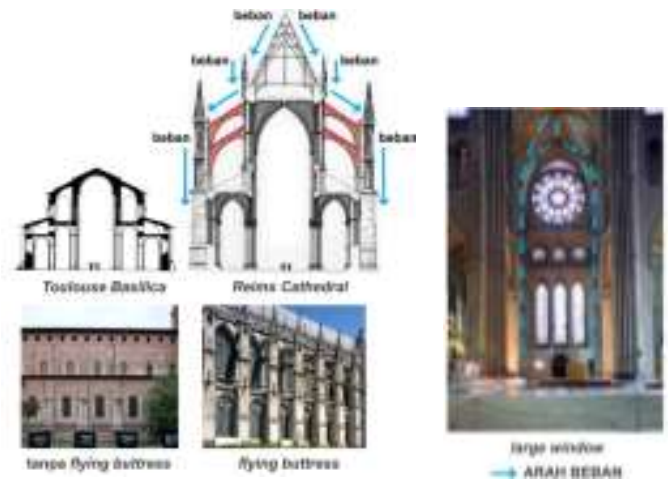

Gambar 4. Struktur flying buttress dan pointed arch menopang beban atap dan dinding gereja Gothic Sumber: Pengembangan dari http://mappinggothic.org/building/1044, diakses 4 Mei 2014
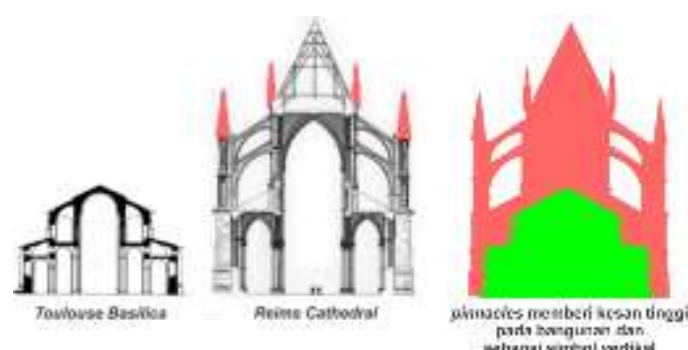

Gambar 5. Pinnacles memberikan kesan tinggi dan sebagai symbol vertikal gereja Gothic

Sumber: Pengembangan dari

http://mappinggothic.org/building/1044, diakses 4 Mei 2014

Dengan bentuk yang tinggi dan besar pada Reims Cathedral, flying buttres berfungsi untuk menstabilkan dinding atas. Struktur tersebut mentransmisikan tekanan beban dari rib vault ke tanah, tanpa melalui dinding, sehingga konstruksi dinding bangunan menjadi lebih ringan dan jendela memiliki proporsi yang lebih besar. Melihat dari ukuran jendela, Reims Cathedral memiliki jendela yang lebih besar (large windows). Dapat dijelaskan karena beban struktur yang dimiliki gereja Gothic dapat disalurkan melalui vault yang berbentuk pelengkung sudut. Sudut itu membagi beban dengan baik dan menyalurkan ke tanah melalui kolom dan flying buttress, sehingga jendela yang begitu besar bebannya ditopang sendiri oleh dinding. Dengan adanya jendela yang besar itu pula maka ada peningkatan penerimaan pencahayaan alami. Adapun pinnacles gereja Gothic memiliki proporsi yang lebih ramping dan lebih banyak dibandingkan dengan menara yang ada pada gereja Romawi. Hal tersebut memperlihatkan pemberian kesan yang semakin tinggi pada bangunan gereja Gothic, dan ini merupakan bentuk simbolisme vertikal mengenai hubungan Tuhan dengan manusia.

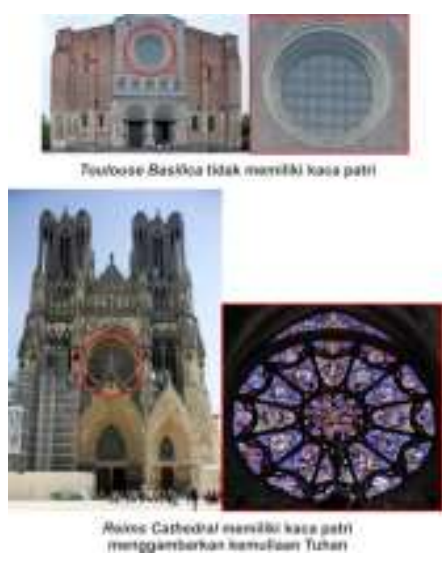

Gambar 6. Stained glass sebagai dekorasi cahaya dalam ruang dan symbol kemuliaan Tuhan gereja Gothic

Sumber: Pengembangan dari http://mappinggothic.org/building/1044, diakses 4 Mei 2014
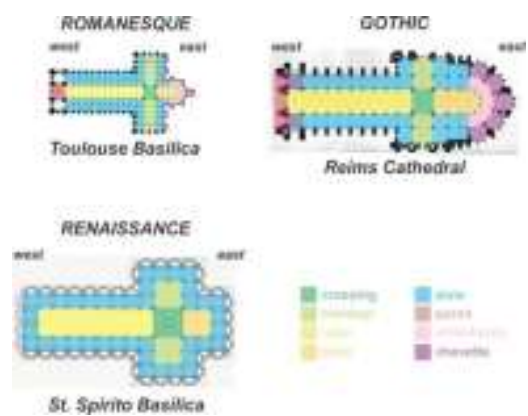

Gambar 7. Denah gereja Romawi, Gothic,

Renaissance berbentuk salib sebagai perlambang iman Kristiani

Sumber: Pengembangan dari

http://mappinggothic.org/building/1044, diakses 4 Mei 2014

Kaca patri atau stained glass berfungsi sebagai sarana dekorasi cahaya di dalam gereja Gothic 
melalui bidang jendela yang cukup luas atau lebar dalam menerima cahaya dengan berbagai ornamen yang indah. Sedangkan denah atau floor plan dari gereja Gothic merupakan adaptasi dari gaya Romawi dan diadaptasi juga oleh gaya Renaissance, gaya arsitektur yang muncul setelah era arsitektur Gothic. Ukuran denah mengalami peningkatan pada gereja Gothic dan meningkat lagi pada gereja Renaissance. Denah seperti ini menyimbolkan tentang iman Kristiani (Salib Kristus).

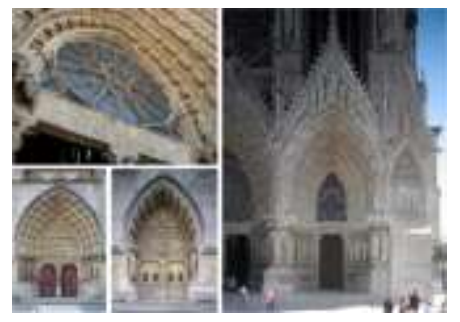

Gambar 8. Dekorasi yang semarak pada gereja Gothic

Sumber: Pengembangan dari

http://mappinggothic.org/building/1044, diakses 4 Mei 2014

Flamboyant decoration pada gereja Gothic merupakan suatu hasil dari semangat perubahan para seniman gereja di mana setiap dekorasi seni haruslah ditempa dengan semangat yang sejati hingga mewujudkan suatu hal yang detail bahkan terkesan rumit. Filosofi ini berbeda dengan gereja Romawi yang terkesan suram.

\subsection{Pembahasan Kajian Teori}

Rib vault berbentuk pointed arch dengan flying buttress adalah struktur yang menjadikan bangunan gereja Gothic memiliki kesan ringan dan tinggi, adapun pinnacles dengan jumlah yang banyak juga memberikan kesan semakin tinggi. Large windows memberikan peningkatan cahaya alami yang masuk dalam gereja Gothic. Stained glass memberikan gambar/simbol religi iman Kristiani serta estetika pada gereja Gothic dengan dekorasi cahaya yang menembus melalui kaca patri. Flamboyant decoration merupakan semangat perubahan para seniman gereja Gothic dimana setiap dekorasi seni sebagai perlambang persembahan yang tertinggi kepada Tuhan. Floor plan berbentuk salib menyimbolkan tentang iman Kristiani.
Seluruh analisa di atas secara konsisten menjelaskan bahwa bangunan gereja gaya Gothic memiliki struktur dan elemen bangunan yang merupakan evolusi dari arsitektur gereja Romawi, ada usaha peningkatan vertikalitas dan pemasukan cahaya serta penyimbolan pada bangunan gereja arsitektur Gothic. Peningkatan vertikalitas dan pemasukan cahaya serta penyimbolan pada bangunan gereja dapat dirangkum menjadi suatu konsep yaitu: verticalism, transparent, religious symbolism.

Verticalism dapat diartikan suatu garis maya pada suatu bentuk yang tegak lurus dengan permukaan bumi dari bawah ke atas atau sebaliknya dan memiliki proporsi tinggi yang lebih panjang dari lebarnya. Transparent diartikan tembus cahaya, dan cahaya dapat masuk ke dalam suatu ruang dengan bebas. Religious symbolism berarti segalanya yang mengandung maksud tertentu yang bersifat keagamaan baik itu yang terlihat maupun yang tidak terlihat. Usaha untuk membuat proporsi bangunan menjadi lebih tinggi dan megah (skala Tuhan) dengan efek ruang yang suci yang dibentuk dari pancaran cahaya Illahi (pencahayaan alami matahari) yang sarat akan penyimbolan kisah tentang Tuhan (lepasnya kejahatan dari dunia) dilengkapi dengan kemewahan ornamen bangunan yang sangat detail memperlihatkan bahwa arsitektur gereja Gothic ditujukan hanya untuk memberi kehormatan, kemuliaan yang setinggi-tingginya untuk Tuhan.

Arsitektur gereja Romawi kurang merepresentasikan bahwa bangunan yang nantinya akan disebut sebagai rumah Tuhan itu harus penuh dengan kemuliaan. Mulia berarti paling tinggi, dipandang yang paling utama, untuk itu arsitektur gereja Gothic meletakkan konsep bahwa bangunan sebagai rumah Tuhan itu harus "paling; paling tinggi, paling megah dan paling mewah. Ketiga konsep di atas (verticalism, transparent, religious symbolism) jika diabstraksikan lagi dengan kata kunci "paling" (paling tinggi, paling megah, paling mewah) didapatkanlah satu kata yaitu dignity. Dignity dalam kamus Oxford Advanced Learner's Dictionary of Current English tahun 1984 yaitu: "true worth; the quality that earns or deserves respect" atau "high or honourable rank", dan jika dihubungkan dengan konsep dan teori 
arsitektur gereja Gothic dapat diartikan bahwa: arsitektur gereja Gothic memberikan kualitas sejati yaitu hormat dan kemuliaan yang setinggi-tingginya untuk Tuhan yang tertuang pada desain gereja.

\subsection{Pembahasan Kajian Metode}

Metode untuk mewujudkan teori dignity harus sejalan dengan konsep yang sudah dirangkum yaitu verticalism, transparent, dan religious symbolism. Bicara konsep verticalism, bangunan gereja Gothic dirancang untuk memiliki tinggi yang melebihi dari gaya arsitektur pada era arsitektur Romawi dan lebih besar dimana perbandingan proporsi dari façade dan struktur bangunan memiliki tinggi yang lebih panjang dari lebarnya. Hal tersebut berhubungan dengan filosofi yang pada era itu merupakan zaman yang mengarah total pada Yang Maha Tinggi. Ada hubungan antara Tuhan yang dilambangkan berada di atas dan manusia yang dilambangkan berada di bawah. Bangunan gereja Gothic menjadi perlambang hubungan vertikal antara Tuhan Yang Maha Tinggi di atas dan manusia yang berdosa di bawah. Usaha untuk mempertinggi bangunan gereja Gothic dan menyimbolkan hubungan langsung kepada Tuhan Yang Maha Tinggi dapat disebut sebagai heighten. Terlihat dari struktur bangunan yang berupa vault dan jendela yang berbentuk pointed arch, serta adanya pinnacles yang menjulang tinggi dengan jumlah yang banyak.

Bangunan yang tinggi menjulang membutuhkan beban yang lebih ringan serta struktur yang dapat menyalurkan beban dengan baik. Bangunan gereja arsitektur Gothic dirancang untuk memperingan beban bangunan dengan membagi gaya beban. Usaha untuk memperingan struktur bangunan dan mendukung konsep heighten dimana gereja gaya Gothic haruslah menjulang tinggi dapat disebut sebagai mitigate. Usaha untuk memperingan struktur bangunan terlihat dari penggunaan struktur flying buttress yang dapat menyalurkan beban dari atap dengan baik karena beban tersebut dapat terbagi, menjadikan dinding bangunan tidak terlalu terbebani (dinding menopang beratnya sendiri). Bentuk struktur dari vault dan jendela yang berpointed arch juga dapat memecah beban bangunan dan menyalurkannya ke bawah atau ke struktur flying buttress dengan baik.

Berbicara mengenai transparent, interior bangunan gereja arsitektur Gothic dirancang untuk lebih terang. Ada usaha untuk memasukkan cahaya matahari dengan intensitas yang jauh lebih banyak sehingga jauh dari kesan suram. Usaha untuk memasukkan cahaya alami matahari sebanyak mungkin ke dalam bangunan sehingga ruang gereja Gothic menjadi lebih terang dapat disebut dengan brighten. Terlihat dari jendela pada bangunan gereja Gothic memiliki bentuk dan ukuran yang besar dan diletakkan di tempat yang tinggi, dimaksudkan agar cahaya matahari dapat masuk lebih banyak. Karena dinding pada bangunan gereja Gothic tidak mendapat beban yang terlalu berat dari atap dan juga beban tersebut sudah terbagi dengan struktur flying buttress, maka bentuk dan ukuran jendela yang terletak di dinding dapat menjadi lebih besar.

Sebagai bangunan gereja dan sesuai dengan filosofinya pada saat itu (abad 12 - 15) dimana bangunan gereja merupakan lambang hubungan yang vertikal antara manusia yang di bumi dengan Tuhan Yang Maha Tinggi, maka bangunan gereja arsitektur Gothic sarat dengan simbol-simbol iman Kristiani (religious symbolism). Usaha menampilkan simbolsimbol yang melekat pada bangunan gereja Gothic dapat disebut dengan symbolize. Hal tersebut terlihat mulai dari penyimbolan bahwa bangunan gereja Gothic memiliki pinnacles yang melambangkan hubungan vertikal antara manusia di bawah dengan Tuhan Yang Maha Tinggi di atas. Penyimbolan juga ada pada stained glass dan decoration yang memiliki corak dan warna yang mana melukiskan kisahkisah Kristiani adalah perlambang kemuliaan Tuhan. Adapun sinar matahari yang masuk melalui kaca patri menjadi perlambang cahaya Illahi (berkat dalam gereja). Floor plan pada sangat jelas berbentuk salib menyajikan symbol ke-Kristenan.

Berdasarkan pembahasan di atas, maka metode untuk mewujudkan teori dignity (memberikan kehormatan setinggi-tingginya pada Tuhan melalui bangunan gereja) yaitu dengan cara: 1) heighten atau mempertinggi/memperamping; 2) mitigate atau memperingan; 3) brighten atau memperterang cahaya alami dalam ruang; 4) symbolize atau menyimbolkan Tuhan Yang Maha Tinggi dan ke-Kristenan. 


\subsection{Pembahasan Kajian Aplikasi}

Aplikasi dari bangunan gereja Gothic dengan teori dignity serta konsepnya yang berupa: 1) vertikalism; 2) transparent; 3) religious symbolism dengan metodenya: 1) heighten; 2) mitigate; 3) brighten; 4) symbolize, dapat dilihat kembali melalui ciri-ciri bangunan gereja Gothic yang sudah terbangun. Karena arsitektur gereja Gothic asal mulanya berkembang di Prancis, maka penulis mengambil 5 gereja /cathedral dengan arsitektur Gothic yang ada di Perancis untuk dibahas mengenai ciri-cirinya yang sesuai dengan pembahasan teori, konsep, serta metode yang ditemukan di awal. Kelima cathedral tersebut yaitu: 1) Amiens Cathedral; 2) Beauvais Cathedral; 3) Chartres Cathedral; 4) Reims Cathedral; 5) Troyes Cathedral.

Pembahasan dilakukan dengan membuat tabel yang berisikan masing-masing kelima Cathedral tersebut di atas dengan pembuktian ciri-ciri dari bangunan gereja dengan arsitektur Gothic. Adapun pembuktian tabel tersebut ada pada lampiran. Terlihat dari 5 (lima) cathedral tersebut kecocokan antara teori, konsep, metode dengan aplikasinya yaitu berupa ciriciri yang melekat pada arsitektur gereja gaya Gothic, antara lain: denah bangunan berbentuk salib, pointed arch (pelengkung sudut), ribbed vault (kubah berusuk), flying buttress (penopang layang), pinnacles (hiasan puncak menara), flamboyant decoration (dekorasi semarak), large windows filled (jendela besar), with rich stained glass (dengan kaca patri).

\section{KESIMPULAN}

Berdasarkan seluruh pembahasan di atas, dapat disimpulkan bahwa teori dari arsitektur gereja Gothic yaitu dignity. Dignity dapat diartikan sebagai hasil evolusi dari gereja era Romawi dimana ada kesalehan tentang keyakinan Kristiani sehingga gereja Gothic dibangun dengan maksud memberi kehormataan dan kemuliaan setinggi-tingginya pada Tuhan. Kata dignity didapat dari mengabstraksikan variabelvariabel konsep yang terdiri dari verticalism, transparent, dan religious symbolism. Sedangkan metode untuk mewujudkan konsep tersebut adalah heighten, mitigate, brighten, symbolize. Metode-metode tersebut teraplikasi pada elemen-elemen struktur gereja Gothic yaitu ribbed vault, pointed arch, flying buttress, pinnacles, large windows, stained glass, cross form floor plan. Berikut tabel hubungan antara teori, konsep, metode dan aplikasi arsitektur gereja Gothic.

Tabel 1. Tabel Hubungan antara Teori, Konsep, Metode, Aplikasi Arsitektur Gereja Gothic

\begin{tabular}{|c|}
\hline TEORI \\
\hline DNGNITY \\
\hline KONSEP \\
\hline VERTICALISM TRANSPARENT $\begin{array}{c}\text { RELIGIOUS } \\
\text { SYMBOLISM }\end{array}$ \\
\hline METODE \\
\hline HEIGHTEN MITIGATE BRIGHTEN \\
\hline APLIKASI \\
\hline $\begin{array}{l}\text { 1. CHOSS FLOOR PLAN } \\
\text { 2. POINTED ARCH } \\
\text { 3. RIBEED VAUUT } \\
\text { 4. FLYNG BUTTRESS } \\
\text { 5. PINNACLES } \\
\text { 6. FLAMBOYANT DECORATION } \\
\text { 7. LARGE WINDOWS FILLED, } \\
\text { 8. WITH RICH STAUNED GLASS }\end{array}$ \\
\hline
\end{tabular}

\section{REFERENSI}

Cole, E. (2002). The grammar of architecture. New York: Little, Brown and Company.

Kutha, N. R. (2010). Metodologi penelitian: kajian budaya dan ilmu sosial humaniora pada umumnya. Pustaka Pelajar: Yogyakarta.

Murray, S., Tallon, A., \& O'neill, R. (n.d.). Mapping gothic France. Retrieved May 3, 2014, from http://mappinggothic.org/.

Poynter, E.J. (Eds.). (October 3, 2010) Architecture gothic and rennaisance. London: Sampson Low, Marston, Searle \& Rivington. Diambil dariGutenberg Ebook Architecture https://www.gutenberg.org/files/33837/33 837-h/33837-h.htm.

Wahid, J., Alamsyah, B. (2013). Teori arsitektur; suatu kajian perbedaan pemahaman teori barat dan timur. Yogyakarta: Graha Ilmu. 


\section{LAMPIRAN}

1
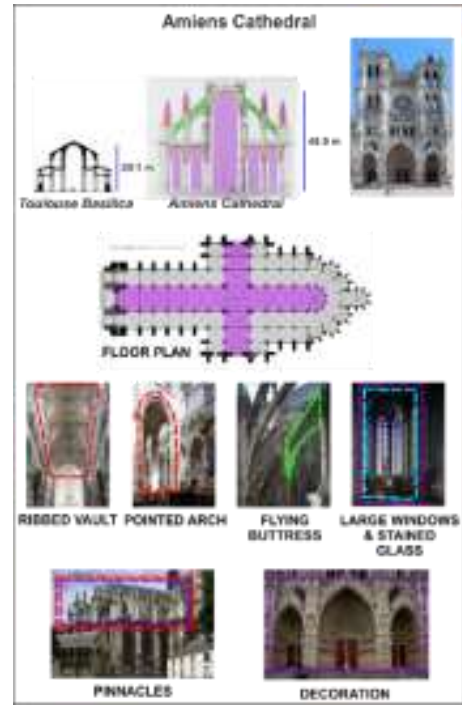

2

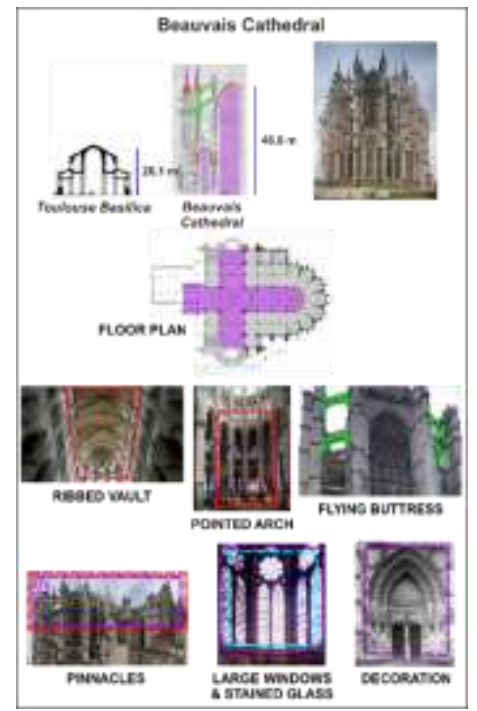

3

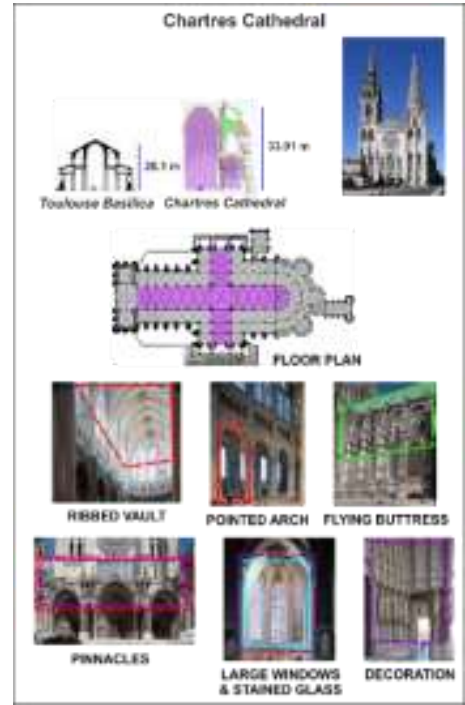

4

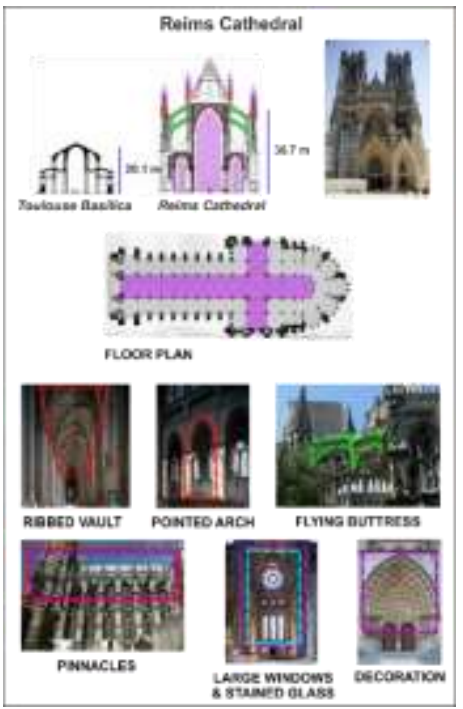

5
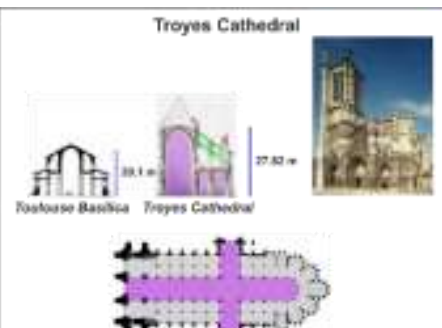

poos pus
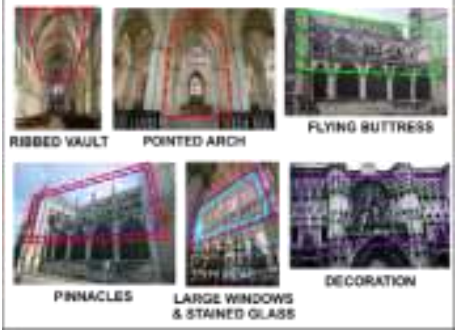

Gambar 9. Aplikasi dari Teori, Konsep dan Metode Arsitektur Gereja Gothic pada Amiens Cathedral ${ }^{1}$, Beauvais Cathedral ${ }^{2}$, Chartres Cathedral ${ }^{3}$, Reims Cathedral $^{4}$, Troyes Cathedral ${ }^{5}$ 